\title{
Effect of Suggested Rehabilitation Program with Mechanical Traction on Basketball Player's Low Back Spine Pain Treatment and Efficiency of Skillful Performance
}

\author{
Asaad A. El-Kiki', Waleed M. Hedya ${ }^{2}$ \\ ${ }^{1}$ Professor of basketball training at the Sport Games Training Department, Faculty of Sport Education for Men, Alexandria \\ University, Egypt. \\ ${ }^{2}$ Assistant professor at Biological Sciences and sports health Department, Faculty of Sports Education for Men, Matrouh \\ University, Egypt.
}

\begin{abstract}
Abstract. [Purpose] The purpose of this study was to examine the effect of a suggested rehabilitation program with mechanical traction on basketball player's low back spine pain treatment and efficiency of skillful performance. [Subjects and Methods] The study sample comprised twenty four players (17-22 years-old) from Port-Said different basketball clubs who's registered in the Egyptian basketball federation season 2016/2017, 2017/2018, 2018/2019 and diagnosed with low back spine pain. The sample was selected from men basketball players, the study was applied in July 2017-March 2018, Port-Said - Egypt (each player receive 12 treatment sessions / 3 weeks except therapeutic exercise programs receive 30 units ). The sample was divided to two subsamples the control sample was treated with the traditional treatment method separately (therapeutic exercise programs, TENS/EMS, ultrasound (US), heating/cooling, manual therapy/mechanical vibrating massage and mechanical low back spine traction), the experimental sample was treated as same as the control sample with addition that the mechanical low back spine traction treatment was done at the same time with TENS/EMS, heating/cooling and manual therapy/ mechanical vibrating massage vibrating massage. Low back pain was measured using three different low back range of motion (ROM) parameters and basketball skill test racing circuit, for each patient pre and post traditional and suggested rehabilitation program. [Results] The experimental sample was higher in the results of low back pain reduction than the control sample; moreover it was higher than the control sample in the results of basketball skillful performance. Conclusion: It appears that mechanical traction and TENS/EMS, heating/cooling and manual therapy/electric massage, that done at the same time on low back spine have a beneficial effect on reducing the pain and increasing efficiency of skillful performance amongst basketball players.
\end{abstract}

Keywords: Low back, Mechanical traction, Pain, Spine, Treatment;

\section{Introduction}

$\mathrm{T}$ The lower back tolerates the greatest load when humans perform a variety of movements and considered as the central axis of the body during our movements in everyday life (Hayashi 2004; Papi et al., 2017). Low back pain is a problem that affects $80 \%$ of adults at some point in life, it is amongst the top 10 primary reasons of consultation with internists and, causing a great effect in productivity and economy (Almeida and Kraychete 2017).

Pain is not the only consequence of low back experienced by patients. Pain is associated with function, with physical movements triggering pain, while pain, in turn, causes limitations in physical function (Castrogiovanni and Musumeci 2017).

In patients with low back pain, several movements had been documented as common to cause pain in the lower back such as lumbar flexion, extension, and rotation. When certain movements alleviate pain, this will cause fear and the individual tends to avoid these movements (Vincent et al., 2013; Meulders et al., 2015).

Avoiding painful movements of the low back spine for a long time may decrease the activity of the back and abdominal muscles thereby decline their strength and control that lead to limitations of physical performance (Suri et al., 2015). 
Physical activity has been recommended to be both a possible risk factor and a preventive factor for low back spine pain. There is confirmation for high physical workloads being harmful on the back. Occupational exposure, strenuous workload, frequent lifting, bending and twisting and extreme sport activities are risk factors for low back pain. The harmful impact on the back is dependent on individual factors such as physical fitness or health perceptions (Heneweer et al., 2009). Low back spine pain is a relatively common complaint in in basketball players, due to excessive load on the lumbar spine, high pressure movements and twisting and landing, these are examples of the underlying mechanisms that may result in the development of low back pain (Pasanen et al., 2016).

Therapeutic Exercise has been found to be one of the most effective treatments for declining pain and increasing function in low back pain. The many other health benefits of exercise, along with the little risk of causing harm, make it a first-line treatment for mechanical low back pain (Ojoga et al., 2013).

Transcutaneous electrical nerve stimulation (TENS) is used to treat the low back pain, stimulation was effective in decreasing low back pain and a significant improvement was observed in patients with lumbar pain treated with active TENS (Buchmuller et al., 2012).

The effects of electrical muscles stimulation (EMS) in low back pain treatment, (EMS) is a time-efficient, safe, jointfriendly technology and appears to be an effective training tool for reducing low back pain (Kemmler et al., 2017).

Therapeutic ultrasound (US) is a widely used treatment for low back pain. When a patient has ultrasound therapy, the objective is to transport heat and energy to body parts under the skin, to decrease pain and increase the speed of recovery (Ebadi et al., 2014).

Nonpharmacological treatment for musculoskeletal injury should perfectly decrease pain and related edema, if any, while also encouraging muscle healing in order to help a return to normal function and activity. Cold therapy, also known as cryotherapy is often used in this context. Many studies have shown that cooling can be an efficient in decreasing the pain of low back and improving its function. Moreover the effects of heat therapy include pain relief, increases in blood flow and metabolism, and increased elasticity of connective tissue (Malanga et al., 2015). Many studies are documented the safety and efficacy of heating and cooling combination therapy on patients with low back pain (Kim et al., 2015).

Furlan et al. (2015) study results documented that, the massage is an effective therapy for LBP. Acute, sub-acute and chronic LBP had enhancements in pain with massage only in the short-term follow-up.

In order to decompress a joint, it is necessary to distract it in the opposite direction to the compressive force. Where a joint has become stiff and immobile, gentle mobilization at the point of distraction helps to improve mobility in the joint and allow the natural mechanisms, which keep joints healthy to operate freely. Mechanical joint traction of the low back therapy enable patient for an optimal relief (Patnaik 2018).

The present study aimed at assessing the effect of a qualifying program with mechanical traction on basketball player's low back spine pain treatment.

\section{Materials and methods}

\section{Study sample}

The study sample comprised twenty four men (17-22 years-old) diagnosed with low back spine pain, had no issues of blood pressure, pulse, and breathing, they also had no consciousness or sensory disorders. The sample was selected from basketball players, the study was applied in July 2017- March 2018, Egypt.

\section{Study domains}

\section{Study time}

Period: From July 2017 to March 2018.

\section{Study place}

Study was performed at health and sport scientific center and at Ramsis sporting club, Port Said, Egypt.

\section{Experimental setup and working}

The study sample was divided to two subsamples the control sample was treated with the traditional treatment method separately (therapeutic exercise programs, TENS / EMS, ultrasound (US), heating/cooling, manual therapy/mechanical vibrating massage and mechanical low back spine traction) the experimental sample was treated as same as the control sample with addition that the mechanical low back spine traction treatment was done at the same time with TENS/EMS, heating/cooling and mechanical vibrating massage.

\section{Therapeutic exercise programs}

Active isotonic and isometric strengthening exercises were performed to strengthen the frontal abdominal muscles (musculus obliquus externus abdominis, musculus 
obliquus internus abdominis, musculus rectus abdominis), deep abdominal muscles (musculus psoas major, musculus psoas minor, musculus iliacus, musculus quadratum lumbarum), and back muscles (musculi dorsi, musculus erector spinae, musculi transverso-spinales, musculi interspinales, musculi intertransversarii). For the hamstrings, lumbar extensors, and hip flexors, a group of stretching exercises was performed (Şahin et al., 2018). The exercise program lasted for three weeks and was performed at least five days per week, two exercises per day, with each exercise repeated at least $10 \times 3$ times.

\section{Transcutaneous electrical nerve stimulation (TENS)}

Brief-intense TENS (BITENS), pulses of long duration $(0.9 \mathrm{~ms})$ are set at high frequency $(150 \mathrm{~Hz})$ and sensory, motor, and nociceptor fibers are stimulated. This treatment was applied for 30min/session (Rongsawad and Ratanapinunchai 2018). Participant received 6 sessions in the first week of the treatment program.

\section{Electrical muscles stimulation (EMS) training:}

The electrical stimulator delivered a constant current symmetrical biphasic waveform with pulse duration of $100 \mu \mathrm{s}$ and a frequency of $50 \mathrm{~Hz}$. Each EMS contraction lasted 10 seconds and a rest interval was detected between each contraction. The EMS intensity (mA) was set according to each participant's tolerance level (Karthikeyan and Moorthy 2016). EMS session was applied for 35 and 40min/session for the second and third week's respectively, participant received 3sessions/week.

\section{Ultrasound (US)}

In US therapy (frequency: $1 \mathrm{MHz}$, intensity: $1.5 \mathrm{~W} / \mathrm{cm} 2$, duration: 8min) (Yildiz et al., 2015). This treatment was applied for 12 sessions of the treatment program.

\section{Heating/cooling therapy}

A total of 12 treatment sessions were administered to each patient during a period of three weeks, six days/week during the first week $(1 \times 6)$. In the first week the cooling therapy with cold gel pack applied directly to the skin of the injured area for 30 minutes at $15{ }^{\circ} \mathrm{C}$ (Shehata and Fareed 2013). Following two weeks the patients will receive three separated sessions/week (1x3) using heating and cooling combination therapy with gel pack that attached to the injured area for 35 and $40 \mathrm{~min}$, and its temperature will be cycled ten times and nine started with $45^{\circ} \mathrm{C}$ then changed to $15^{\circ} \mathrm{C}$. This temperature was chosen to provide stimulation of cold and hot receptors (Kim et al., 2015).

\section{Manual therapy and mechanical vibrating massage}

Massage therapy group received deep stroking, pulling, friction, rolling and wringing (Kamalia et al., 2014). Each massage type was done for three minutes, totally fifteen minutes in each session for five types, in the first week the massage therapy applied 6 sessions / week. Following two weeks the patients will receive 3 sessions / week.

Mechanical vibrating massage was done twelve sessions/ three weeks, six sessions were applied during the first week, and three separated sessions for second and third weeks. Mechanical vibrating massage was applied for a total period of 30,35 and 40 minute in an intermittent pattern, involving 120,180 and 240 second of massage and 30 second of relaxation for first, second and third weeks respectively, and this will be cycled twelve, ten and nine times respectively.

\section{The mechanical traction}

Twelve sessions were administered to each patient for three weeks, six sessions were applied during the first week, and three separated sessions for second and third weeks. Traction was applied by initial with a force equivalent to $30 \%$ of the body weight at the first week, increased by $40 \%$ of the body weight at the second week up to a maximum $50 \%$ of the patient's body weight with the last week, according to the patient's acceptance (Koçak et al., 2018). Traction was applied for a total period of 30, 35 and 40 minute in an intermittent pattern, involving 120,180 and 240 second of traction and 30 second of relaxation for first, second and third weeks respectively, and this will be cycled twelve, ten and nine times respectively.

\section{Tools:}

In order to achieve the aim of the study, two tools were utilized to collect the data. These tools are as follows:

Tool I: Measuring test: As lumbar spine Right/left Rotation was measured using the goniometer (Hwanga et al., 2017), the lumbar spine extension / flexion and Right/left lateral flexion were measured using the clinometer android application (Hwanga et al., 2017; Jayavel et al., 2017).

Tool II: Basketball skill test racing circuit (Figure2.1): includes speed dribbling, passing, layup and shooting skills. Start and finish point were controlled by stopwatch. Greatest score was recorded after two trials.

The circuit includes 4 skill stations. Layup with both hands (A), slalom dribbling (B), passing (C), and stop jam shot (D). Instructions on the racing circuit were; 
1: Run and start stopwatch to get the ball under the basket.

2: Dribbling with the left hand turn around the cone and make left hand layup, if not recorded score under the basket, repeat this with the right hand.

4: Dribbling to station B and do slalom dribbling using both hands (distance between two successive cones is 1 meter).
5: Dribbling to station $\mathrm{C}$, chest pass for the hit until the target is achieved.

6: Dribbling to the free throw line and stop for a jam shot, if it is recorded run to the finish. If jam shot is not recorded, get the rebound and score under the basket and run to the finish (Bavli 2016).

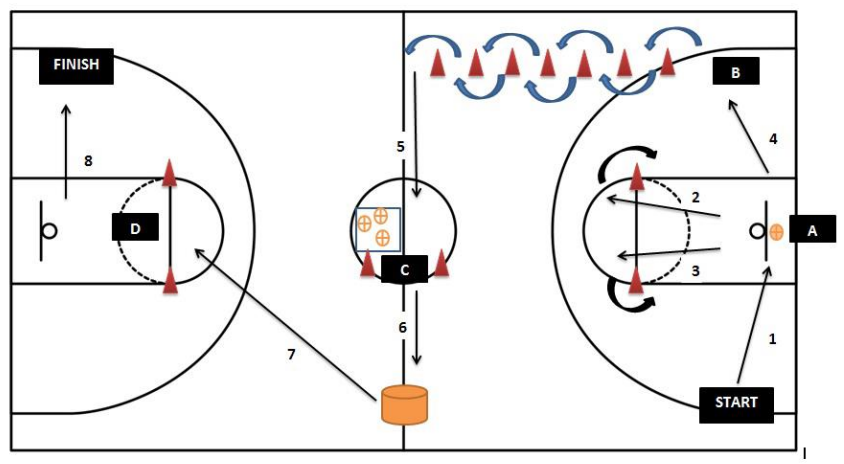

Figure 2.1. Basketball skill test racing circuit.

\section{Results and discussion}

No study participant left the research project for any reason. No side effects or complications were observed during the treatment.

Data collected using different measuring tools, revealed that there were improvements in back pain and skillful performance measurements in pre compared to the post measuring for the control and experimental samples with different traditional and suggested rehabilitation programs. The maximum improvement was detected with the experimental sample, compared with the control sample, after three weeks of treating using different rehabilitating programs. Results were presented in Tables 3.1-3.6 and Figure 3.1.

In patients with low back pain, the therapeutic exercise programs remains the first-line treatment that should be routinely used; the aim of this therapy is to improve function, and to prevent disability from getting worse (Shipton 2018).

TENS study results is in line with Jauregui et al. (2016) who reported that, the use of TENS is an easy, cost effective, non-invasive, and non-harmful modality that may reduce back pain. As a result of reduced back pain and the patients will continue to remain active, and maintain a healthier lifestyle. TENS is able to hinder the transmission of pain signals directly at the level of the spinal cord. Moreover, intense somatic input projects to the central gray matter in the midbrain which in turn stimulates a powerful descending inhibitory control system. These inhibitory influences (spinal and supraspinal) would block the entrance to ascending pain signals and stop the pain significantly.

According to Ahmad and Hasbullah (2015) study results documented that, EMS was effective in strengthening skeletal muscle, because during the penetration of impulses to the muscle, the Central Nervous System (CNS) activates the smallest motor neurons and with increasing level of intensity, larger motor neurons were activated. During EMS training, $90 \%$ of the muscles were activated simultaneously giving contraction to muscle and the muscle contraction was stronger and more intense than a voluntary exertion can do alone.

Ultrasonic energy causes soft tissue molecules to vibrate from exposure to the acoustic wave. This improved molecular motion produces frictional heat, thus increasing tissue temperature. This heating is increased collagen extensibility, rise nerve conduction velocity, change local vascular perfusion, rise enzymatic activity, and change contractile activity of skeletal muscle (Ebadi et al., 2011).

Heating and cooling therapy study results are in line with Kim et al., (2015) who reported that, heating and cooling combination therapy beneficial effects may be intermediated by changing blood flow, declining inflammation, induction of contraction and relaxation of blood vessels, declining edema, or declining stiffness of the muscle. The temperatures $15{ }^{\circ} \mathrm{C}$ and $45{ }^{\circ} \mathrm{C}$, do not burn or damage the skin and has stimulation effect on cold and hot receptors on the skin of patients with low back pain. 
Massage study results is in line with Al-Sadek et al. (2017) who reported that, for patients with low back pain both of the massage that was done with the hands over the patient's back region, or that was done using a mechanical device there is confirmation showing that massage is beneficial in decreasing pain intensity and improving the back function. The effects of massage are improved if joined with exercise and education.

The enhancement in functional result from the application of traction may be because of increasing intervertebral space, supporting lumbar spine, or increasing blood flow to the spine, traction is cost effective and actual effective method for relieving low back pain owing to disc pathology and stable lumbar fractures as it works on distraction of the disc spaces and relieving the compression on the nerves (Al-Sadek et al., 2017).
Data analysis indicated significant variations $(\mathrm{P}<0.01)$ in low back pain measurements among two different samples, using two different treating programs,

The maximum improvement was detected with the experimental sample, compared with the control sample, these results are in line with Jagtap and Shanmugam (2014); who reported that various traditional approaches are used in treating joint pain but their study shows that ultrasound and exercises alone shows minimal effect in reduction of pain than compared to traction along with ultrasound and exercises. Traction was more effective in decreasing pain and improving quality of life than using conventional therapy alone.

Table 3.1. Mean, standard deviation and t-test between control and experimental samples for demographic characteristics

\begin{tabular}{|c|c|c|c|c|c|}
\hline \multirow{2}{*}{ Demographic characteristics } & \multicolumn{2}{|c|}{ Control } & \multicolumn{2}{|c|}{ Experimental } & \multirow{2}{*}{ t-value } \\
\hline & Mean & $\pm \mathrm{SD}$ & Mean & $\pm \mathrm{SD}$ & \\
\hline Age & 19.92 & 2.57 & 19.75 & 3.22 & 0.14 \\
\hline Training age & 9.08 & 3.65 & 9.50 & 3.87 & 0.27 \\
\hline Body height & 184.50 & 6.30 & 183.92 & 6.16 & 0.23 \\
\hline Body weight & 80.42 & 5.07 & 79.42 & 4.21 & 0.53 \\
\hline
\end{tabular}

T critical at alpha $0.05=1.72 *$

Table 3.2. Mean, standard deviation, difference, difference $(\%)$ and t-test between control and experimental samples measurements before the program

\begin{tabular}{|c|c|c|c|c|c|c|c|}
\hline \multirow{2}{*}{ Measurements } & \multicolumn{2}{|c|}{ Control } & \multicolumn{2}{|c|}{ Experimental } & \multirow{2}{*}{ Difference } & \multirow{2}{*}{$\begin{array}{c}\text { Difference } \\
(\%)\end{array}$} & \multirow{2}{*}{ t-value } \\
\hline & Mean & $\pm \mathrm{SD}$ & Mean & $\pm \mathrm{SD}$ & & & \\
\hline Lumbar spine extension / flexion & 62.83 & 3.76 & 63.25 & 4.54 & 0.42 & 0.66 & 0.24 \\
\hline Lumbar spine Right/left lateral flexion & 33.17 & 4.69 & 32.88 & 4.45 & 0.29 & 0.89 & 0.16 \\
\hline Lumbar spine Right/left Rotation & 34.08 & 3.32 & 33.58 & 2.78 & 0.50 & 1.49 & 0.40 \\
\hline Basketball skill test racing circuit & 103.58 & 9.79 & 105.83 & 9.43 & 2.25 & 2.17 & 0.57 \\
\hline
\end{tabular}

T critical at alpha $0.05=1.72 *$

Table 3.3: Mean, standard deviation, difference, enhancing $(\%)$ and t-test between pre and post the program for control sample measurements

\begin{tabular}{|c|c|c|c|c|c|c|c|}
\hline \multirow{2}{*}{ Measurements } & \multicolumn{2}{|c|}{ Control pre program } & \multicolumn{2}{|c|}{ Control post program } & \multirow{2}{*}{ Difference } & \multirow{2}{*}{$\begin{array}{c}\text { Enhancing } \\
(\%)\end{array}$} & \multirow{2}{*}{$\mathrm{t}$-value } \\
\hline & Mean & $\pm \mathrm{SD}$ & Mean & $\pm \mathrm{SD}$ & & & \\
\hline Lumbar spine extension / flexion & 62.83 & 3.76 & 98.17 & 4.95 & 35.34 & 56.23 & $19.68^{*}$ \\
\hline Lumbar spine Right/left lateral flexion & 33.17 & 4.69 & 52.92 & 2.87 & 19.75 & 59.55 & $12.44 *$ \\
\hline Lumbar spine Right/left Rotation & 34.08 & 3.32 & 52.75 & 2.45 & 18.67 & 54.77 & $15.68 *$ \\
\hline Basketball skill test racing circuit & 103.58 & 9.79 & 59.92 & 6.92 & -43.66 & -42.16 & $12.61 *$ \\
\hline
\end{tabular}

Table 3.4: Mean, standard deviation, difference, enhancing $(\%)$ and t-test between pre and post the program for experimental sample measurements

\begin{tabular}{|c|c|c|c|c|c|c|c|}
\hline \multirow{2}{*}{ Measurements } & \multicolumn{2}{|c|}{ Experimental pre program } & \multicolumn{2}{|c|}{ Experimental post program } & \multirow{2}{*}{ Difference } & \multirow{2}{*}{$\begin{array}{c}\text { Enhancing } \\
(\%)\end{array}$} & \multirow{2}{*}{ t-value } \\
\hline & Mean & $\pm \mathrm{SD}$ & Mean & $\pm \mathrm{SD}$ & & & \\
\hline Lumbar spine extension / flexion & 63.25 & 4.54 & 116.54 & 3.89 & 53.29 & 84.26 & $30.89 *$ \\
\hline Lumbar spine Right/left lateral flexion & 32.88 & 4.45 & 57.33 & 1.97 & 24.45 & 74.40 & $17.40^{*}$ \\
\hline Lumbar spine Right/left Rotation & 33.58 & 2.78 & 58.33 & 1.60 & 24.75 & 73.70 & $26.74 *$ \\
\hline Basketball skill test racing circuit & 105.83 & 9.43 & 51.42 & 7.53 & -54.41 & -51.42 & $15.63^{*}$ \\
\hline
\end{tabular}




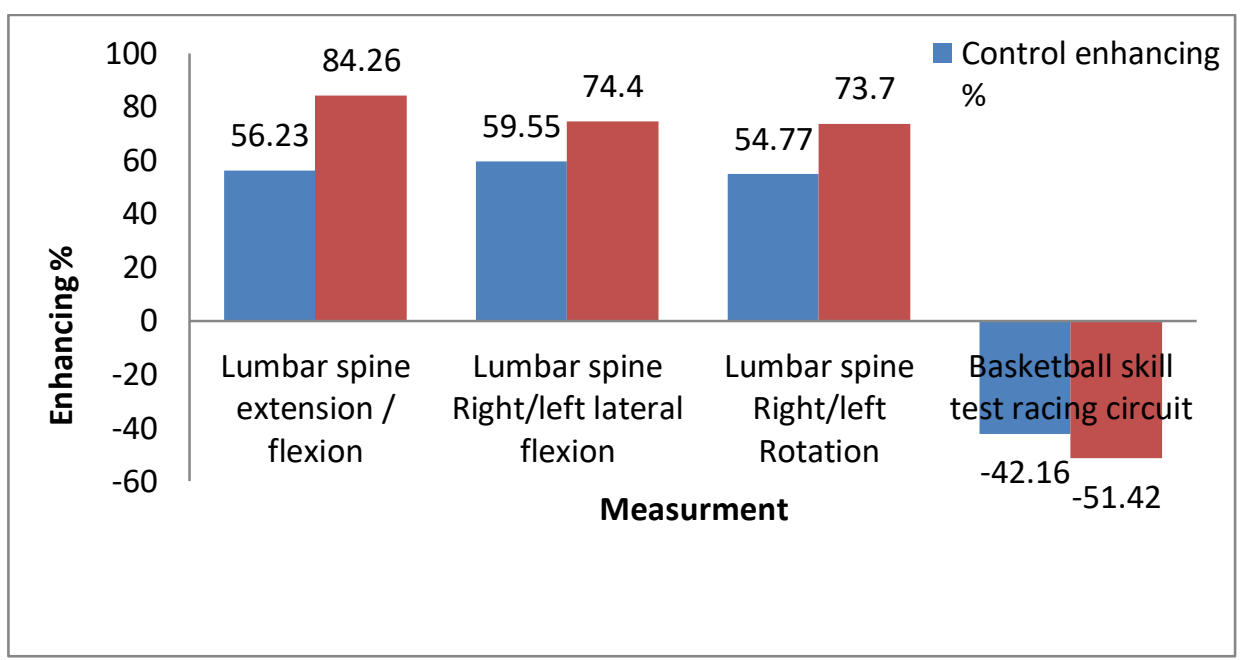

Figure3.1. Enhancing \% between pre and post the program for control and experimental sample measurements.

Table3.5. Mean, standard deviation, difference, difference $(\%)$ and t-test between control and experimental samples measurements after program

\begin{tabular}{|c|c|c|c|c|c|c|c|}
\hline \multirow{2}{*}{ Measurements } & \multicolumn{2}{|c|}{ Control } & \multicolumn{2}{|c|}{ Experimental } & \multirow{2}{*}{ Difference } & \multirow{2}{*}{$\begin{array}{c}\text { Difference } \\
(\%)\end{array}$} & \multirow{2}{*}{ t-value } \\
\hline & Mean & $\pm \mathrm{SD}$ & Mean & $\pm \mathrm{SD}$ & & & \\
\hline Lumbar spine extension / flexion & 98.17 & 4.95 & 116.54 & 3.89 & 18.38 & 18.72 & $10.11^{*}$ \\
\hline Lumbar spine Right/left lateral flexion & 52.92 & 2.87 & 57.33 & 1.97 & 4.42 & 8.35 & $4.39 *$ \\
\hline Lumbar spine Right/left Rotation & 52.75 & 2.45 & 58.33 & 1.60 & 5.58 & 10.58 & $6.60^{*}$ \\
\hline Basketball skill test racing circuit & 59.92 & 6.92 & 51.42 & 7.53 & 8.50 & 16.53 & $2.88^{*}$ \\
\hline
\end{tabular}

Table3.6. Correlation between lumbar spine measurements and basketball skill test for control and experimental samples pre and poet the program

\begin{tabular}{|c|c|c|c|c|}
\hline \multirow{2}{*}{ Correlation } & \multicolumn{3}{|c|}{ Control sample } & \multicolumn{2}{|c|}{ Experimental sample } & Pre & Post & Pre & Post & 0.983 & 0.987 & 0.954 & 0.918 \\
\hline Lumbar spine extension / flexion and Basketball skill test & 0.978 & 0.776 & 0.957 & 0.971 \\
\hline Lumbar spine Right/left lateral flexion and Basketball skill test & 0.987 & 0.983 & 0.969 \\
\hline Lumbar spine Right/left Rotation and Basketball skill test & 0.935 \\
\hline
\end{tabular}

Data analysis indicated significant variations $(\mathrm{P}<0.01)$ in knee measurements among three different experimental groups, using three different treating programs.

The maximum improvement was detected with the third experimental groups, compared with the second and the first groups, these results are in line with Jagtap and Shanmugam (2014); who reported that various traditional approaches are used in treating osteoarthritis of knee joint but their study shows that ultrasound and exercises alone shows minimal effect in reduction of pain than compared to traction along with ultrasound and exercises. Traction was more effective in decreasing pain and improving quality of life than using conventional therapy alone.

\section{Conclusion}

Maximum improvement in knee measurements was detected with the third experimental groups, compared with the second and the first groups, after six weeks of treating using different treating programs.

\section{References:}

1- Ahmad M. F. and Hasbullah A. H.2015. The effects of electrical muscle stimulation (EMS) towards male skeletal muscle mass. International journal of medical, health, biomedical, bioengineering and pharmaceutical engineering, 9 (12).

2- Almeida D.C. and Kraychete D.C. 2017. Low back pain - a diagnostic approach. Rev Dor. São Paulo, 18 (2):1737.

3- Al-Sadek T., Niklev D. and Al-Sadek A.2017. Traction as consertivw mangment of lower back pain: Case study. Trakia journal of sciences, 1: 92-93.

4- Bavlı Ö. 2016. Investigation into the effects of eight weeks of step aerobic dance practice on static balance, flexibility and selected basketball skills in young basketball players. Journal of education and training studies, 4(5). 
5- Buchmuller A.,Navez M., Milletre-Bernardin M., Pouplin S., Presles E., Lantéri-Minet M., Tardy B., Laurent B., Camdessanché J.P.2012. Value of TENS for relief of chronic low back pain with or without radicular pain. European journal of pain, 16(5):656-65.

6- Castrogiovanni P. and Musumeci G.2017. Which is the best physical treatment for osteoarthritis? Journal of functional morphology and kinesiology, 1: 54-68.

7- Dreisinger T. E., Orlando F.L., and Tucson A.Z. 2014. Exercise in the Management of Chronic Back Pain. The Ochsner Journal, 14:101-107.

8- Ebadi S., Ansari N. N., Henschke N., Naghdi S. and Tulder M. W. V.2011. The effect of continuous ultrasound on chronic low back pain: protocol of a randomized controlled trial. Biomed central, musculoskeletal disorders, 12:59.

9- Ebadi S., Henschke N., Ansari N. N., lah E. F. and Tulder M. W.2014. Therapeutic ultrasound for chronic low-back pain. Cochrane database of systematic reviews.

10- Furlan A. D., Brosseau L., Imamura M., and Irvin E.2017. Massage for low back Pain: A systematic review within the framework of the Cochrane collaboration back review group. SPINE, 27( 17): 1896-1910.

11- Furlan A. D., Giraldo-Prieto M., Baskwill A. and Irvin E.2015. Massage for low back pain. Cochrane database of systematic review.

12- Hayashi Y.2004. Classification, diagnosis, and treatment of low back pain. Journal of the Japan medical association, 47(5): 227-233.

13- Heneweer H., Vanhees L., Picavet H. S. J.2009. Physical activity and low back pain: A U-shaped relation? International association for the study of pain, 143: 21-25.

14- Hwanga D., Leea J. H., Moona S., Parka S. W., Wooa J., Kimb C.2017. The reliability of the nonradiologic measures of thoracic spine rotation in healthy adults. Korean academy of physical therapy rehabilitation science.

15- Jagtap V. and Shanmugam S.2014. Effect of mechanical traction in osteoarthritis knee. International journal of science and research, 3(10).

16- Jauregui J. J., Cherian J. J., Gwam C. U. and Mistry J. B.2016. A meta-analysis of transcutaneous electrical nerve stimulation for chronic low back pain. Surgical technology international.

17- Jayavel A., Misra P., Sivakumar V.2017. Reliability and validity of I handy android application on measurement of lumbar spine movement in patients with low back pain. International journal of clinical skills, 11(3).

18- Kamalia F., Panahib F., Ebrahimic S. and Abbasic L.2014.Comparison between massage and routine physical therapy in women with sub-acute and chronic nonspecific low back pain. Journal of Back and Musculoskeletal Rehabilitation, 27: 475- 480.

19- Kemmler W., Weissenfels A., Bebenek M., Fröhlich M., Kleinöder H., Kohl M. and Stengel S.2017. Effects of Whole-Body Electromyostimulation on Low Back Pain in People with Chronic Unspecific Dorsal Pain: A MetaAnalysis of Individual Patient Data from Randomized Controlled WB-EMS Trials. Hindawi, Evidence-Based Complementary and Alternative Medicine, 8.

20- Kim E. G., o Choi Y. D., Lim C., Kim K. and Lee S.2015. Effect of heating and cooling combination therapy on patients with chronic low back pain: Study protocol for a randomized controlled trial. Biomed central, 16:285.

21- Koçak F. A., Tunç H., Sütbeyaz S. T., Akkuş S., Köseoğlu Be. F., Y1lmaz E.2018. Comparison of the shortterm effects of the conventional motorized traction with non-surgical spinal decompression performed with a DRX9000TM device on pain, functionality, depression, and quality of life in patients with low back pain associated with lumbar disc herniation: A single-blind randomized-controlled trial. Turk J Phys Med Rehab; 64(1):17-27.

22- Malanga G. A., Yan N. and Stark J.2015. Mechanisms and efficacy of heat and cold therapies for musculoskeletal injury. Postgrad Medicine.

23- Meulders A., Karsdorp P. A., Claes N. and Vlaeyen J. W. S. 2015. Comparing counter conditioning and extinction as methods to reduce fear of movement-related pain. Journal of Pain, 16(12): 1353-1365.

24- Ojoga F., Davila U. C. and Marinescu S.2013. Therapeutic Exercise in chronic low back pain. Balneo Research Journal, 4(4).

25- Papi E., Koh W. S. and McGregor A. H. 2017. Wearable technology for spine movement assessment: A systematic review. Journal of Biomechanics 64 :186-197.

26- Pasanen K., Rossi M., Tokola K., Heinonen A., Parkkari J. and Kannus P.2016. Low Back Pain in Young Basketball and Floorball Players. Clinical journal of sport medicine: official journal of the Canadian Academy of Sport Medicine. 
27- Patnaik G.2018. Role of IDD Therapy in the Back and Neck Pain. Journal of Medical Student research, 1: 002

28- Şahin N., Karahan A. Y. and Albayrak İ.2018. Effectiveness of physical therapy and exercise on pain and functional status in patients with chronic low back pain: a randomized-controlled trial. Turk J Phys Med Rehab, 64(1):52-58.

29- Shipton E. A.2018. Physical therapy approaches in the treatment of low back pain. Pain Ther, 7:127-137.

30- Suri P., Fry A.L. and Gellhorn A.C. 2015. Do muscle characteristics on lumbar spine magnetic resonance imaging or computed tomography predict future low back pain, physical function, or performance? A systematic review. American academy of physical medicine and rehabilitation, 7(12): 1269-1281.

31- Vincent H. K., Seay A. N., Montero C., Conrad B. P., Hurley R. W. and Vincent K. R., 2013. Kinesiophobia and fear-avoidance beliefs in overweight older adults with chronic low-back pain: relationship to walking endurance: part II," American journal of physical medicine and rehabilitation, 92 (5):439-445. 